\title{
Non-destructive Prediction Models for Estimation of Leaf Area for Most Commonly Grown Vegetable Crops in Ethiopia
}

\author{
Mikias Yeshitila, Matiwos Taye \\ Department of Plant and Horticultural Sciences, College of Agriculture, Hawassa University, Awassa, Ethiopia \\ Email address: \\ mikiasyes@yahoo.com (M. Yeshitila),taye.matiwos@yahoo.com (M. Taye)
}

\section{To cite this article:}

Mikias Yeshitila, Matiwos Taye. Non-destructive Prediction Models for Estimation of Leaf Area for Most Commonly Grown Vegetable Crops in Ethiopia. Science Journal of Applied Mathematics and Statistics. Vol. 4, No. 5, 2015, pp. 202-216. doi: 10.11648/j.sjams.20160405.13

Received: July 22, 2016; Accepted: August 3, 2016; Published: September 18, 2016

\begin{abstract}
Leaf area (LA) is a valuable key for evaluating plant growth, therefore rapid, accurate, simple, and nondestructive methods for LA determination are important for physiological and agronomic studies. The objective of this study was to develop a model for leaf area prediction from simple non-destructive measurements in some most commonly cultivated vegetable crops' accessions in the country. A field experiment was carried out from May to August of 2014 at 'Hawassa College of Agriculture's research site, using ten selected most commonly grown vegetable species of Potato (Solanum tuberosum. L), Cabbage (Brassica campestris L.), Pepper (Capsicum annuum L.), Beetroot (Beta vulgaris), Swisschard (Beta vulgaris), Sweet potato (Ipomoea batatas L.), Snapbean (Vicia Snap L.) and Onion (Allium cepa). A standard method (LICOR LI-3000C) was also used for measuring the actual areas of the leaves. All equations produced for leaf area were derived as affected by leaf length and leaf width. As a result of ANOVA and multiple-regression analysis, it was found that there was close relationship between actual and predicted growth parameters. The produced leaf area prediction models in the present study are: AREA $\left(\mathrm{cm}^{2}\right)=-16.882+2.533 \mathrm{~L}(\mathrm{~cm})+4.5076 \mathrm{~W}(\mathrm{~cm})$ for Pepper Melka Awaze Variety. AREA $\left(\mathrm{cm}^{2}\right)=-$ $18.943+2.225 \mathrm{~L}(\mathrm{~cm})+5.710 \mathrm{~W}(\mathrm{~cm})$ for Pepper Melka Zale Variety. AREA $\left(\mathrm{cm}^{2}\right)=136.8524+2.68 \mathrm{~L}(\mathrm{~cm})+2.564 \mathrm{~W}(\mathrm{~cm})$ for Sweet-potato. AREA $\left(\mathrm{cm}^{2}\right)=-193.518+8.633 \mathrm{~L}(\mathrm{~cm})+14.018 \mathrm{~W}(\mathrm{~cm})$ for Beetroot. AREA $\left(\mathrm{cm}^{2}\right)=-23.1534+1.1023 \mathrm{~L}(\mathrm{~cm})$ $+16.156 \mathrm{~W}(\mathrm{~cm})$ for Onion. AREA $\left(\mathrm{cm}^{2}\right)=-260.265+27.115(\mathrm{~L}(\mathrm{~cm}) * \mathrm{~W}(\mathrm{~cm}))$ for Cabbage. AREA $\left(\mathrm{cm}^{2}\right)=-422.973+$ $22.752 \mathrm{~L}(\mathrm{~cm})+8.31 \mathrm{~W}(\mathrm{~cm})$ for Swisschard. AREA $\left(\mathrm{cm}^{2}\right)=68.85-13.47 \mathrm{~L}(\mathrm{~cm})+7.34 \mathrm{~W}+0.645 \mathrm{~L}^{2}(\mathrm{~cm})-0.012 \mathrm{~W}^{2}(\mathrm{~cm})$ for Snapbean. $\mathrm{R}^{2}$ values $(0.989,0.976,0.917,0.926,0.924,0.966,0.917$, and 0.966 for the pepper Melka Awaze Variety, Pepper Melka Zale Variety, Sweetpotato, Beetroot, Onion, Cabbage, Swisschard and Snapbean respectively) and standard errors for all subsets of the independent variables were found to be significant at the $\mathrm{p}<0.001$ level.
\end{abstract}

Keywords: Modeling, Leaf Area, Vegetable Crops

\section{Introduction}

The productivity of a crop depends on the ability of plant cover to intercept incident radiation; this is a function of the leaf area available, the architecture of the vegetation cover, and the efficiency of the conversion of energy captured by the plant in the biomass [1]. One estimate of a crop's ability to capture light energy is the leaf area index (LAI).

LAI is the component of crop growth analysis that accounts for the ability of the crop to capture light energy; it is critical for an understanding of the functions of many crop management practices. LAI is important for many areas of agronomy and crop production as a result of its relevance to light interception, crop growth, weed control, crop-weed competition, crop water use, and soil erosion [2]. The concept of the LAI was first introduced by [3] and defined as the ratio of leaf area to a given unit of land area.

Many methods have been used to measure LAI directly, however, these direct methods, including those of tracing, blueprinting, photographing, or using a conventional planimeter, require the excision of leaves from the plants, time-consuming and tedious approaches; furthermore, in some experiments, there is not enough time to make such measurements [4]. All direct methods are similar in that they 
are difficult, extremely labor-intensive, require many replicates to account for spatial variability in the canopy, and are therefore costly in terms of time and money and also destructive. It is therefore not possible to make successive measurements of the same leaf; plant canopy is also damaged, which might cause problems to other measurements or experiments.

Therefore, a nondestructive method for measuring LA is required by agronomists and physiologists. Accurate, nondestructive measurements permit repeated sampling of the same leaves over time and exclude biological variation in destructive methods [5]. Non-destructive estimation of plant leaf areas offers researchers reliable and inexpensive alternatives in horticultural experiments. Non-destructive leaf-area or plant-growth measurements are often desirable because continued use of the same plants over time can reduce variability in experiments as compared with destructive sampling $[6,7,8]$. Additionally, the use of simple linear measurement for predicting the leaf area of horticultural plants eliminates the need for expensive leaf area meters [9]. Non-destructive leaf area estimation also saves time as compared with geometric reconstruction. Determination of the intersection of several leaves is also difficult when leaves remain attached to plants, and repeated measurements are required.

The accuracy of the predictions however, is dependent on the variation in leaf shape within a single plant and between accessions. Plants produce several types of leaves during development. The first few true leaves produced are usually smaller, simpler, and anatomically different from leaves produced later in development [10]. Change in shape and size of successive leaves on a plant are related to physiological changes associated with increasing age of the plant, genetically regulated programs of shoot maturation and a variety of environmental factors [10].

Therefore, a good model is needed for non-destructive leaf area estimation for use in physiological and genetical studies on the vegetative growth phase of (genetically unique) horticultural plants in the country.

\subsection{Statement of the Problem}

Leaf area (LA) is associated with many agronomic and physiological processes including growth, photosynthesis, transpiration, light interception, and energy balance $[11,12$, 13, 14]. Leaf area can be measured by destructive or nondestructive measurements. A common approach for nondestructive leaf area estimation is to develop ratios and regression estimators by using easily measured leaf parameters such as length and width $[15,16]$. Various combinations of measurements and various models relating length and width to area have been utilized in some horticultural crops, for example, fruit trees [17, 18, 19, 20, $21]$ and vegetable crops $[15,5,22,23,14]$.

In Ethiopia, a wide range of Fruit (watermelon, pumpkin, cucumber, pepper, tomato); Inflorescence (broccoli and cauliflower); Bulb (onion, leek, chive and garlic); Tuber (potato and yam); Root (carrot, sweet potato, cassava, beet, rutabaga, kohlrabi, radish); Corm (enset and taro); Stalk (celery, and swiss chard); Seed (beans, peas and corn); Leaf (cabbage, spinach, lettuce) vegetables, indigenous to both temperate and tropical climatic zones are cultivated throughout the year, as small scale and/or commercial crops. Production of these leafy vegetables is a highly profitable enterprise. With increases in demand for leafy vegetables there is a potential for expanding the extent of cultivation.

Different selections of these crops are being grown by researchers and students; however, the estimation of LA of these horticultural crops plants by using mathematical relationships between LA and one or more dimensions of the leaf has received very little attention. Hence, many research studies are devoid of measurement of LAI, which is the most important component of crop growth analysis that accounts for the ability of the crop to capture light energy; it is critical for an understanding of the functions of many crop management practices. LAI is important for many areas of agronomy and crop production as a result of its relevance to light interception, crop growth, ultimately leading to availability of very little information on specific crop growth, yield performance and quality characters of these selections, and the selection of suitable crop varieties. This leads to cultivation of poor quality selections with low yields and low income.

Leaf area can be measured by destructive or nondestructive measurements. Many methods have been devised to facilitate the measurement of LA. However, these methods, apart from their expensiveness and rare availability, also require the excision of leaves from the plants. It is therefore not possible to make successive measurements of the same leaf. Therefore, a nondestructive method for measuring LA is required that permit repeated sampling of the same leaves over time and exclude biological variation in destructive methods [5].

Non-destructive estimation of plant leaf areas offers researchers reliable and inexpensive alternatives in horticultural experiments. Non-destructive leaf-area or plantgrowth measurements are often desirable because continued use of the same plants over time can reduce variability in experiments as compared with destructive sampling $[6,7,8]$. Additionally, the use of simple linear measurement for predicting the leaf area of horticultural plants eliminates the need for expensive leaf area meters [9]. For these reasons, in the past development of mathematical models and equations from linear leaf measurements for predicting total or individual leaf-area has been shown to be very useful in studying plant growth and development. However, the accuracy of the predictions is dependent on the variation in leaf shape within genotypes (between accessions) and environmental factors [10]. Because of this, there is a need to develop a good model for non-destructive leaf area estimation for genetically unique horticultural plants in the country.

\subsection{Objectives of the Study}

Therefore, the aims of this study were 1) to develop a 
model for leaf area prediction from simple non-destructive measurements in some most commonly cultivated vegetable crops' accessions in the country that will be able to accommodate the effect of changes in leaf shape during development and differences in leaf shape between accessions and which could be used for vegetable crops of all accessions and ages without recalibration, 2) to assess the robustness of the model on an independent set of data from (partially) other accessions grown under different environmental conditions and previously developed models of the respective genotypes.

\subsection{Significance of the Study}

Plant leaf area is an important determinant of light interception and associated with many agronomic and physiological processes including growth, photosynthesis, transpiration, energy balance and plant productivity $[11,12$, $13,14]$.

Therefore, a modeling approach involving linear relationships between LA and one or more dimensions of the leaf (length and width) is an inexpensive, rapid, reliable, and nondestructive method for measuring LA and would be more advantageous than many of the destructive methods mentioned above which damage the plant canopy and might cause problems to other measurements or experiments.
Accurate, nondestructive measurements permit repeated sampling of the same leaves over time and exclude biological variation in destructive methods [5]. Additionally, the use of simple linear measurement for predicting the leaf area of horticultural plants eliminates the need for expensive leaf area meters [9].

For these reasons, the development of mathematical models and equations from linear leaf measurements for predicting total or individual leaf-area of particular accession has been shown to be very useful in studying plant growth and development.

\section{Materials and Method}

\subsection{Description of the Study Area}

The experiment was carried out between May and August 2014 at the research field of Hawassa University, College of Agriculture, Awassa located $270 \mathrm{~km}$ south of Addis Ababa with a latitude and longitude of $7^{\circ} 3^{\prime} \mathrm{N} 38^{\circ} 28^{\prime} \mathrm{E}$ at an elevation of 1708 meters [24]. The monthly total rainfall and mean max/min temperatures of each month during the growing season around the experimental site are indicated in Figure 1.

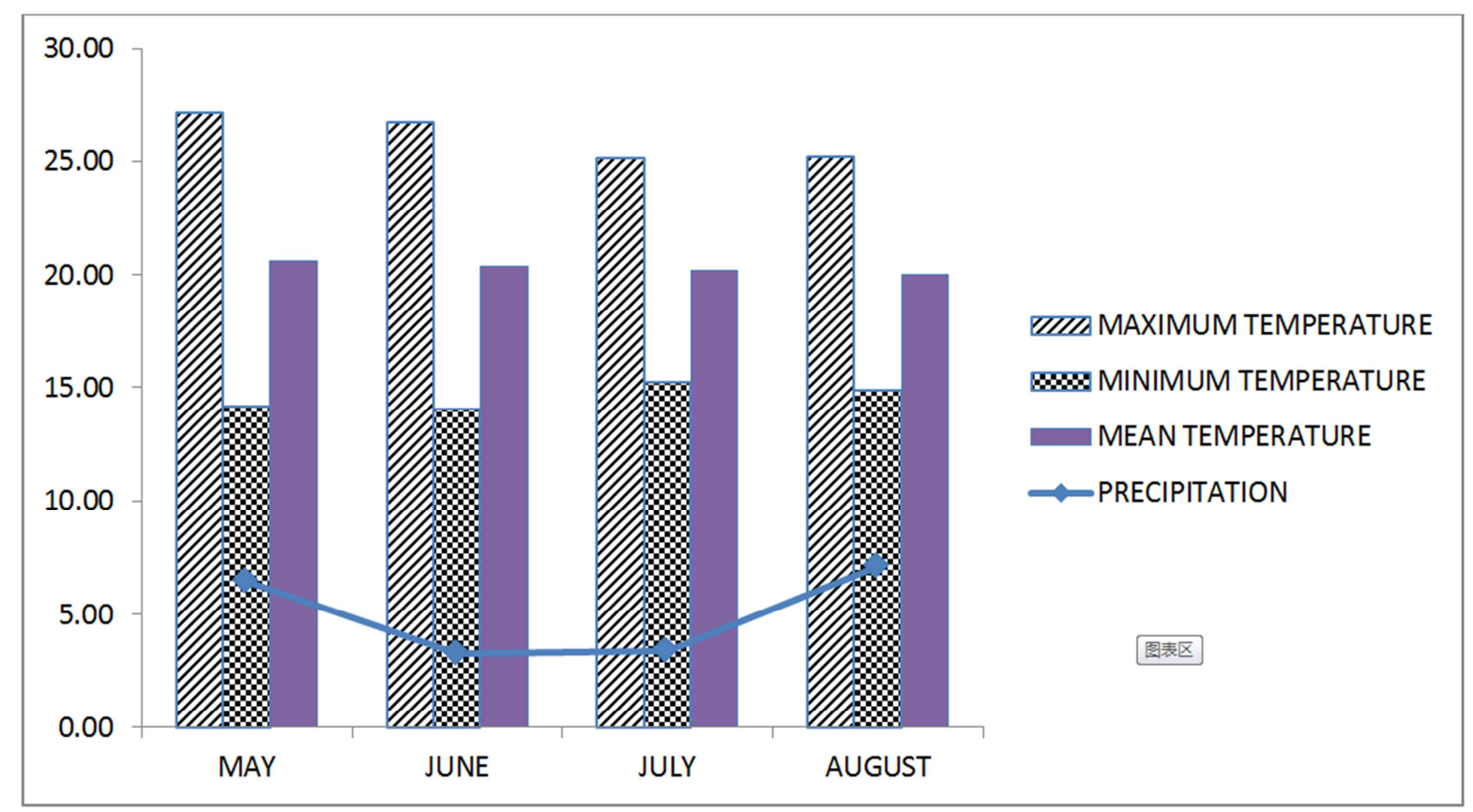

Figure 1. Precipitation, and Maximum, Minimum and Mean Temperature Hours at Hawassa research site during the time of the experiment.

\subsection{Treatments and Experimental Design}

A total of nine treatments were arranged in a randomized block design with three replications/blocks per treatment. Each plot contained 20 plants per species/accession (a total of 60 plants per replication). The whole experiment was also surrounded by border plants of its kind to enhance equal growth circumstances.

\subsection{Crop Management}

Planting was carried out either directly to the main field for those propagated vegetatively or with seed in nursery. Seeds of the varieties were selected based on their wider use in the country and sown in nursery bed prepared from standard growing media mixtures of 1:2:1 ratio of sand, loam and organic matter respectively. All the nursery 
management practices like mulching, shading, watering, thinning and hardening off were carried out as per the standard for vegetable seedlings production. Hardening off the seedlings was carried out starting from one week before transplanting with gradual removal of shade and reducing frequency of water application. Seedlings were transplanted to a well prepared main field planting starting from 4 to 8 weeks based on the type of species. For the sake of calibrating the experiment, all agronomic practices like time of planting, spacing, rate and frequency of fertilizer applications, disease and pest management were maintained as per the recommendation for each of the specific crops as indicated below in Table 1. Other common cultural practices like weeding and cultivation were also applied whenever necessary.

Table 1. Treatment used in the experiment with their recommended agronomic technologies.

\begin{tabular}{|c|c|c|c|}
\hline Edible part classification & Name of vegetables & Varieties & Recommendations \\
\hline Fruit vegetables & Pepper & $\begin{array}{l}\text { Melka Zala } \\
\text { Melka Awaze }\end{array}$ & $\begin{array}{l}100 \mathrm{~kg} \mathrm{P}_{2} \mathrm{O}_{5} \text { and } 100 \mathrm{~kg} \mathrm{~N} \text { (split at transplanting and before flowering) } \\
\text { Spacing: } 70 * 30 \mathrm{~cm}\end{array}$ \\
\hline Root and tubers & $\begin{array}{l}\text { Potato } \\
\text { Sweet potato } \\
\text { Beet root }\end{array}$ & $\begin{array}{l}\text { Local } \\
\text { Local }\end{array}$ & $\begin{array}{l}90 \mathrm{~kg} \mathrm{P}_{2} \mathrm{O}_{5} \text { and } 76 \mathrm{~kg} \mathrm{~N} \text { (split at transplanting and } 60 \text { DAT) } \\
\text { Spacing: } 70 * 30 \mathrm{~cm}\end{array}$ \\
\hline Bulbs & Onion & Nasik-Red & $\begin{array}{l}200 \mathrm{~kg} \mathrm{P}_{2} \mathrm{O}_{5} \text { and } 100 \mathrm{~kg} \mathrm{~N} \text { (split at transplanting and } 40 \text { DAT) } \\
\text { Spacing: } 50 * 20 \mathrm{~cm}\end{array}$ \\
\hline Leafy & $\begin{array}{l}\text { Swiss chard } \\
\text { Cabbage }\end{array}$ & $\begin{array}{l}\text { Fordhook Giant } \\
\text { White Cabbage }\end{array}$ & $\begin{array}{l}112 \mathrm{~kg} \mathrm{P}_{2} \mathrm{O}_{5} \text { and } 112 \mathrm{~kg} \mathrm{~N} \text { (split at transplanting and } 40 \text { DAT) } \\
\text { Spacing: } 70 * 30 \mathrm{~cm} \\
112 \mathrm{~kg} \mathrm{P}_{2} \mathrm{O}_{5} \text { and } 112 \mathrm{~kg} \mathrm{~N} \text { (split at transplanting and before head formation) } \\
\text { Spacing: } 75 * 60 \mathrm{~cm}\end{array}$ \\
\hline Seed & Snap bean & BC4.4 & $\begin{array}{l}46 \mathrm{~kg} \mathrm{P} \mathrm{P}_{5} \text { and } 41 \mathrm{~kg} \mathrm{~N} \text { (split at transplanting and } 40 \text { DAT) } \\
\text { Spacing: } 50 * 20 \mathrm{~cm} \text { with seed rate of } 90 \mathrm{~kg} / \mathrm{ha}\end{array}$ \\
\hline
\end{tabular}

\subsection{Measurements}

Samples for each treatment were selected randomly from different levels of the canopy/tiller at harvest when all plants attained full horticultural maturity. Large to small size leaf samples (at least 20 leaves from each species/cultivars) were collected from fully expanded green leaves and immediately after cutting, leaves were transported to the laboratory. For appropriate measurements damaged plants as well as abnormally grown plants were removed.

Leaf length $\mathrm{L}(\mathrm{cm})$ was measured from lamina tip to the point of intersection of the lamina and the petiole, along the midrib of the lamina, while leaf width $\mathrm{W}(\mathrm{cm})$ was measured from end-to-end between the widest lobes of the lamina perpendicular to the lamina mid-rib.

Actual area was measured with leaf area meter (Licor LI3100 ) by placing the sample leaves on the leaf area meter desktop and by holding flat and secure.

\subsection{Data Management and Analysis}

Prior to calibration, the data set of the calibration experiment was randomly divided into two sets. The first set was used to calibrate the models, the second set for validation. The relation between area and length and width was determined using regression analysis on data of single leaves from the calibration set. Response variable "AREA" was first regressed on explanatory variables L, L2, W, W2, L2W, W2L, LW, (LW)2. The effect of accession was tested as factors in the regression analysis. Selection of the most accurate model for leaf area estimation containing multiple explanatory terms was done with an all-subset regression analysis.
In this method various multiple regression models were tested with an increasing number of explanatory variables, starting with one. For each number of explanatory variables the best fitting models was sorted by increasing adjusted $\mathrm{R}^{2}$. Models with the highest adjusted $\mathrm{R}^{2}$ in which all explanatory variables contributed significantly to the fit of the model was further analyzed.

Mean Square Error (MSE) and the value of the coefficients were calculated by multiple regression analysis and the final model was selected based on the combination of the highest $\mathrm{R}^{2}$ and lowest MSE. An F-test was used to check if the model fit improved significantly by addition of these explanatory variables or factors [25].

Validation of the models was performed on the validation set of the calibration experiment and on data of the validation experiment. Linear regression analysis with calculated single leaf area as an explanatory variable and measured single leaf area as response variable was used to test various models. Both one-way and two-way ANOVA analysis was performed to compare values of measured and calculated total plant leaf area of the total data set of the calibration experiment. Regression analyses were conducted using the EXCEL, SPSS and SigmaPlot 8.0 software packages.

\section{Result and Discussion}

In this study attempt was carried out to develop and validate non-destructive leaf area prediction model for most commonly grown vegetables of Potato (Solanum tuberosum L), Cabbage (Brassica campestris L.), Pepper (Capsicum annuum L.), Beetroot (Beta vulgaris), Swisschard (Beta vulgaris), Sweetpotato (Ipomoea batatas L.), Snapbean 
(Vicia Snap L.) and Onion (Allium cepa) (Figure 2).

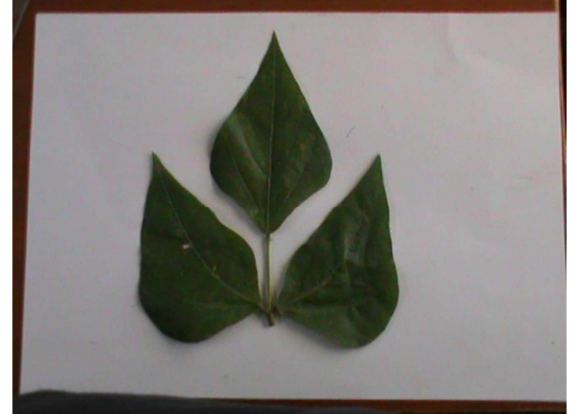

Snapbean

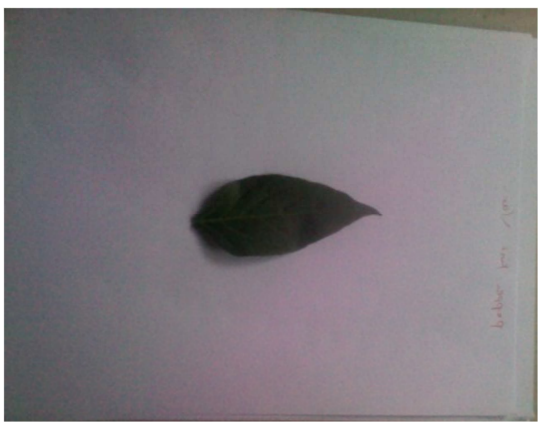

Pepper

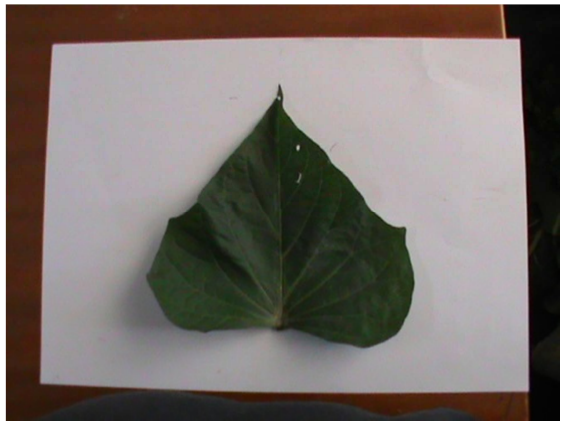

Sweetpotato

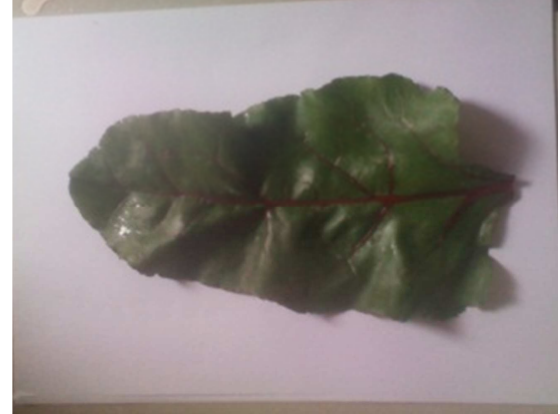

Beet root

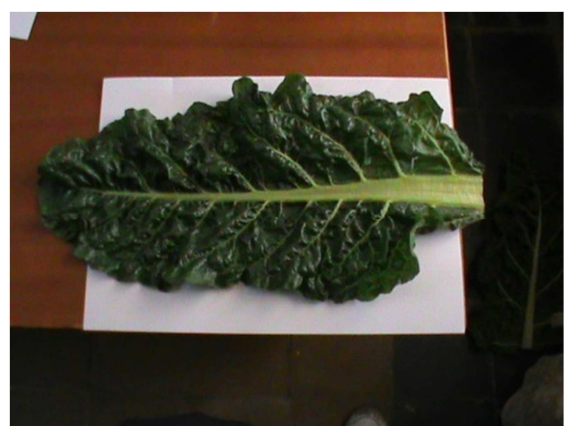

Swisschard

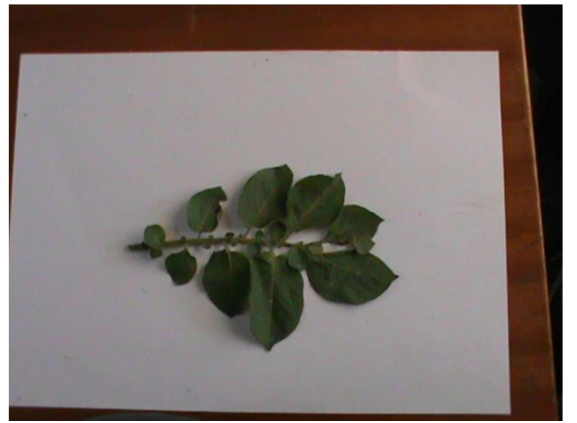

Potato

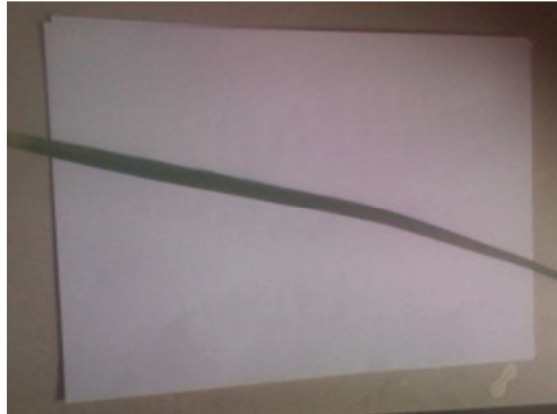

Onion

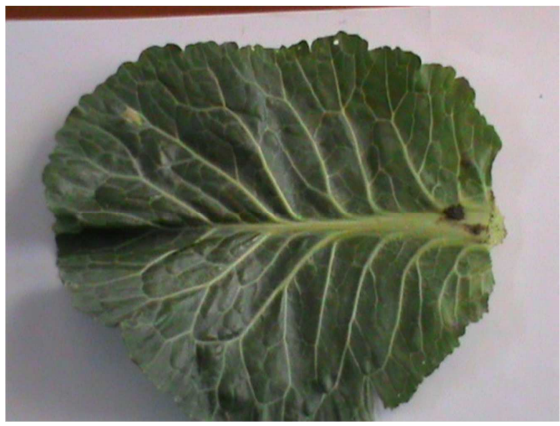

Cabbage

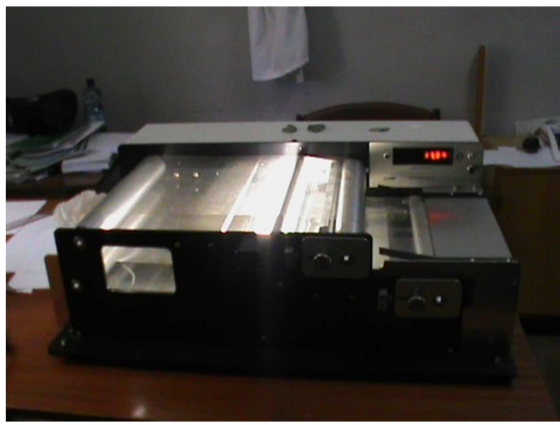

LI-COR 3100

Figure 2. Leaf images of the vegetables used in the experiment.

Many researchers have reported that leaf area can be estimated by linear measurements such as leaf width and leaf length in the following plants: pepper [5], swisschard, beetroot and onions [26], potato [27], cabbage [27] and Snapbeans [28].

The same authors found that there were close relationships between leaf area value, leaf length and leaf width for these plants. In this study multiple regression analysis was used for determination of the best fitting equations for estimation of leaf area in the most commonly grown vegetable species in Ethiopia. The study showed similar results with the previously conducted models in that most of the variations in leaf area values were explained by the selected parameters (length, and width).

However, due to variations that exist among the numerous varieties, the models developed in this experiment have differences with the previously developed ones.

In this experiment, all the equations produced for leaf area were derived as affected by leaf length and leaf width. As a result of ANOVA and multiple-regression analysis, it was found that there was close relationship between actual and predicted parameters. The internal validity of the models was tested by coefficient of determination $\left(\mathrm{R}^{2}\right)$, mean square error (MSE), the prediction sum of squares (PRESS), DurbinWatson Statistic, Normality test, K-S Statistic, and Constant Variance Test. Residuals were analyzed to determine the presence of outliers and non-constant error variance.

The produced leaf area prediction models in the present study are narrated below in the subsequent sub-chapters of the result:

\subsection{Leaf Area Model for Two Pepper Varieties}

Regression equations that incorporate leaf length and width have been generally chosen for their simplicity and accuracy. Since, these measurements are nondestructive. A 
very close relationship between actual and predicted leaf area for the two pepper varieties was found in this study (Figure $3,4,5$ and 6).

A total of 40 leaves from the two Capsicum accessions were measured for leaf area, length and width in the calibration experiment. For the MelkaAwaze pepper variety Area of the leaves ranged from 7.44 to $40.57 \mathrm{~cm}^{2}$, length from 4.75 to $12.5 \mathrm{~cm}$ and width from 2.5 to $5.5 \mathrm{~cm}$. For the Melka Zala pepper variety Area of the leaves ranged from 12.34 to $31.37 \mathrm{~cm}^{2}$, length from 6.15 to $10.5 \mathrm{~cm}$ and width from 3.0 to $5.0 \mathrm{~cm}$.

To develop a method to predict leaf area from length and width measurements dependent of accessions, regression analysis was performed on a set of 21 leaves measured in the calibration experiment (calibration set). The best fitting model for both of the two varieties was obtained with PLANE multiple regression equation (Pepper Variety
MelkaAwaze $\mathrm{R}^{2}=0.99 ; \mathrm{MSE}=1.2154 ; P<0.0001$ and Pepper Variety Melka Zala $\mathrm{R}^{2}=0.98 ; \mathrm{MSE}=1.0984$; $P<0.0001$ ) contained two variables and reads (Table 2; Model 1 and 2):

$$
\begin{aligned}
& \text { AREA }\left(\mathrm{cm}^{2}\right)=-16.8821+2.5330 \mathrm{~L}(\mathrm{~cm})+4.5076 \mathrm{~W}(\mathrm{~cm})(1) \\
& \text { AREA }\left(\mathrm{cm}^{2}\right)=-18.9428+2.2250 \mathrm{~L}(\mathrm{~cm})+5.7101 \mathrm{~W}(\mathrm{~cm})
\end{aligned}
$$

Table 2. The equation of leaf area $L A=y 0+(a \times L)+(b \times W)$ for Capsicum sp. Tested.

\begin{tabular}{lllll}
\hline Genotypes & $\mathbf{y 0}+\mathbf{S E}$ & $\mathbf{a}+\mathbf{S E}$ & $\mathbf{b}+\mathbf{S E}$ & $\mathbf{R}^{2}$ \\
\hline $\begin{array}{l}\text { Melka } \\
\text { Awaze }\end{array}$ & $-16.882+1.034$ & $2.533+0.224$ & $4.508+0.586$ & 0.99 \\
Melka Zala & $-18.943+1.646$ & $2.225+2.225$ & $5.710+0.655$ & 0.98 \\
\hline
\end{tabular}

LA: leaf area, L: leaf length, W: leaf width, SE: Standard Error. $* * * \mathrm{R}^{2}$ and all $\mathrm{SE}$ values are significant at $\mathrm{P}<0.001$

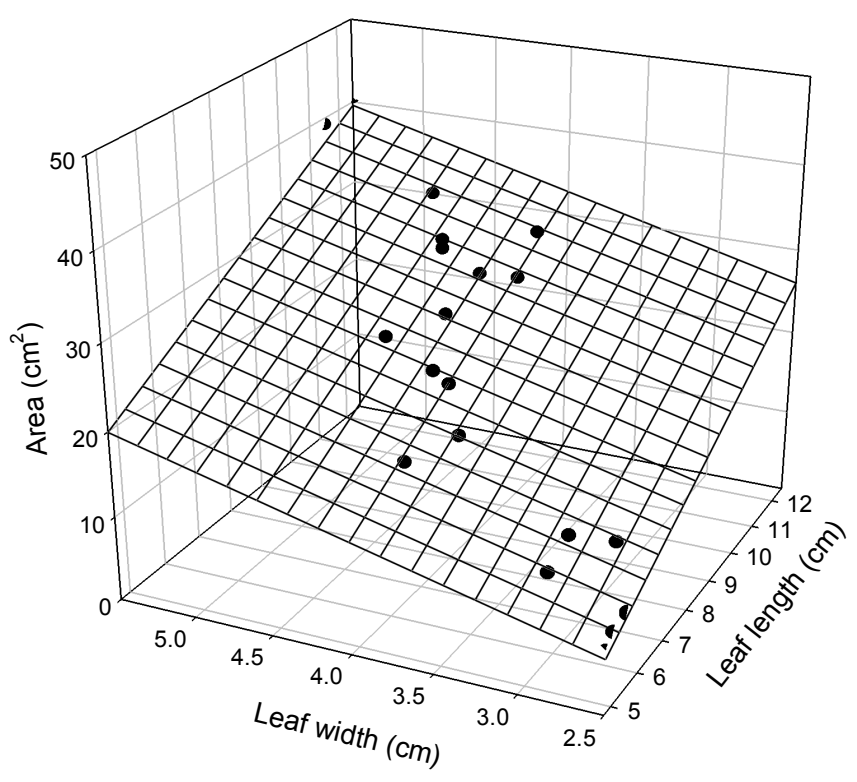

Figure 3. Model calibration for Pepper MelkaAwaza.

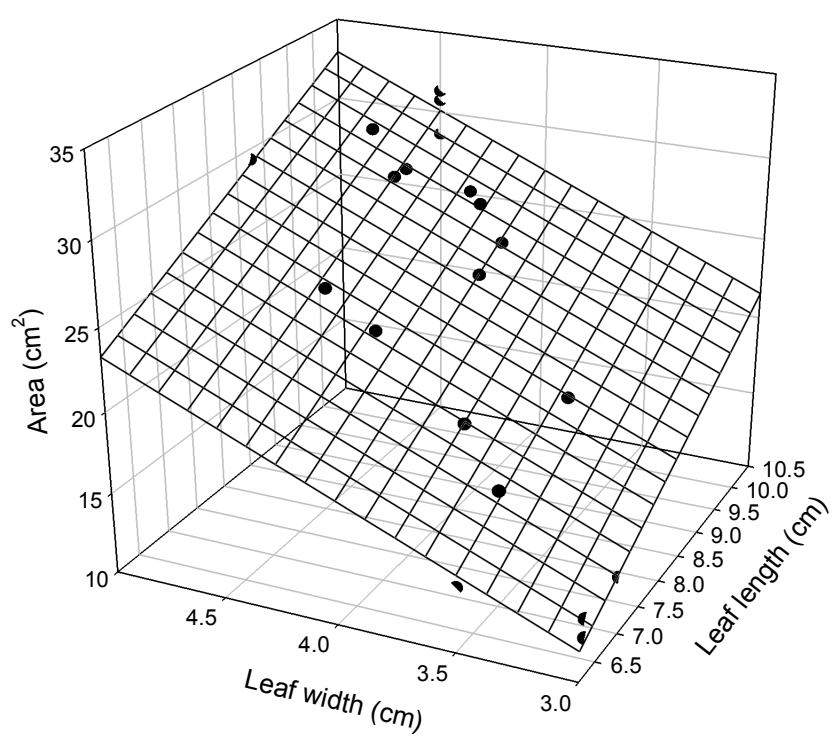

Figure 4. Model calibration for Pepper MelkaZala. 


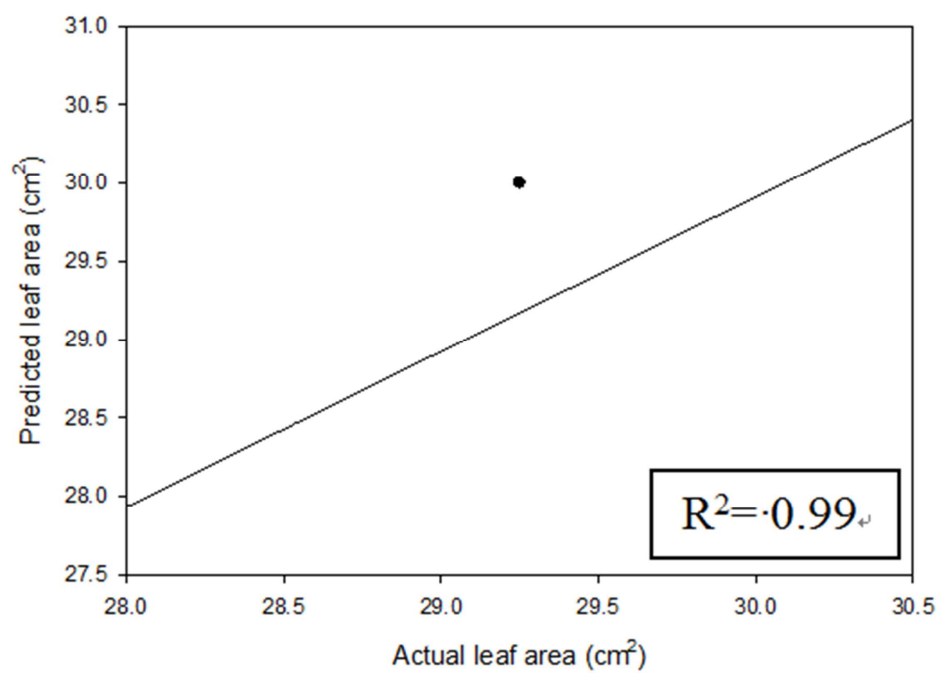

Figure 5. Relationship between actual ( $x$ axis) and predicted (y axis) leaf area in Pepper MelkaAwaze.

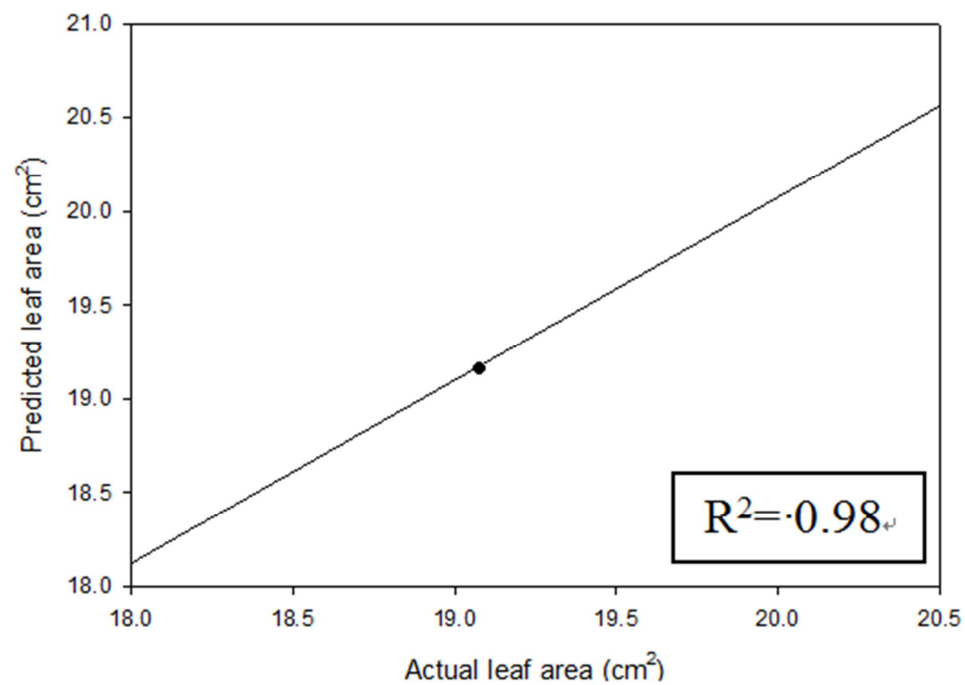

Figure 6. Relationship between actual (x axis) and predicted (y axis) leaf area in Pepper MelkaZala.

The slight difference between the models for the two Capsicum varieties in the present study was not surprising and due to differences in size and shape of leaves of the two varieties as explained by the slop/ratio relation between leaf width (W) and leaf length (L) of single leaves from the two measured Capsicum accessions measured in the calibration experiment (Figure 7).

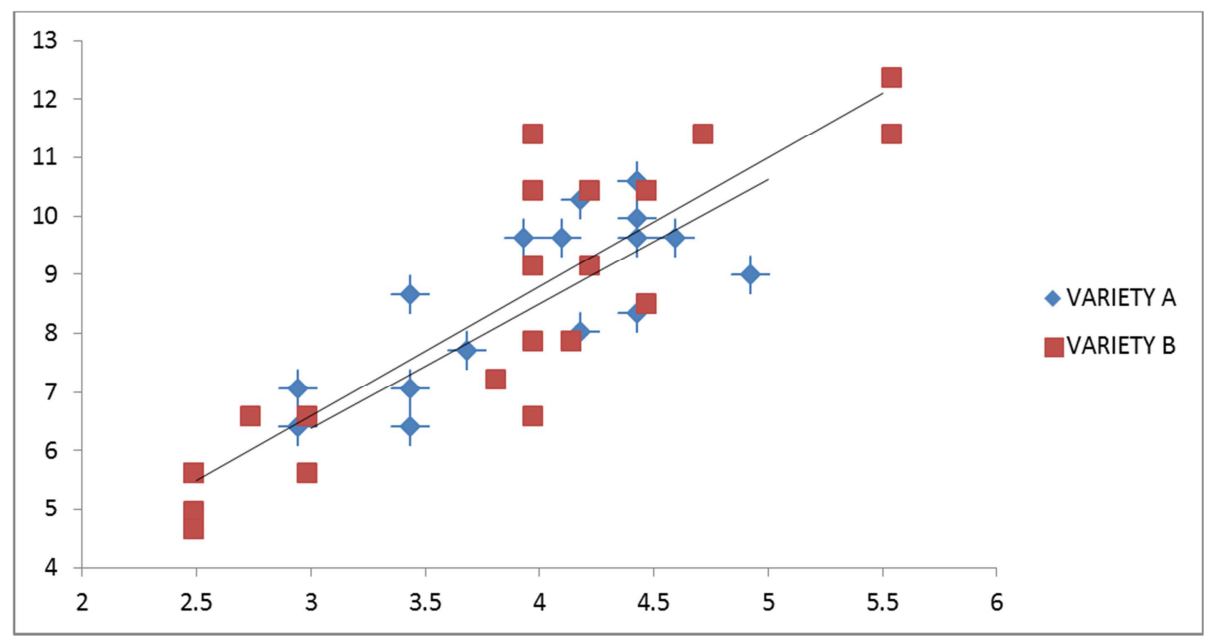

Figure 7. The length and width of leaves of the two accessions: The lines represent linear regression lines for the different accessions: ' $A=M e l k a A w a z e$ ' $(L=$ $\left.2.13 \mathrm{~W} ; R^{2}=0.62\right)$, and ' $B=$ MelkaZala' $\left(L=2.2 W ; R^{2}=0.80\right)$. 
Earlier study was conducted by [5] to develop a method to estimate leaf area from non-destructive measurements in four Capsicum annuum L. accession. Based on the result from testing of various fitting models dependent on both plant age and accession, leaf area predicted from the product of length and width was the best fitting. In spite of the variations observed in the Coefficients of determination and parameter of estimates, the results were similar with earlier study conducted on Capsicum accessions in that the best-fit models were best predicted using both leaf length and width.

\subsection{Leaf Area Model for Swisschard, Beetroot, Sweet Potato and Potato}

Multiple regression analysis was used for determination of the best fitting equation for estimation of the leaf area in most commonly grown root and tuber crops of sweet-potato, beet-root and potato and on the leafy vegetable swiss-chard. It was found that most of the variations in leaf area values were explained by the selected parameters which are leaf length and leaf width (Table 3 ). A very close relationship between actual and predicted leaf area for the crop species was found in this study (Figure 8, 9, 10, 11, 12, 13, 14 and $15)$.

The best fitting model for both of the two species was obtained with PLANE multiple regression equation (Sweetpotato $\mathrm{R}^{2}=0.92 ; \mathrm{MSE}=5.1261 ; P<0.0001$ and Beet root $\mathrm{R}^{2}$ $=0.93 ; \mathrm{MSE}=136.7204 ; P<0.0001$ Potato $\mathrm{R}^{2}=0.966 ; \mathrm{MSE}$ $=0.674 ; P<0.0001$ and Swiss-chard $\mathrm{R}^{2}=0.92 ; \mathrm{MSE}=$ 2643.3; $P<0.0001)$ contained two variables and reads (Model 3, 4, 5 and 6):

For the case of sweet-potato, the best fitting model was obtained when area data was transformed with logarithmic transformation.

Table 3. The equation of leaf area $L A=y 0+(a x L)+(b \times W)$ for Sweet-potato, beetroot, potato and swisschard sp.

\begin{tabular}{lllll}
\hline Genotypes & $\mathbf{y 0}+\mathbf{S E}$ & $\mathbf{a}+\mathbf{S E}$ & $\mathbf{b}+\mathbf{S E}$ & \multicolumn{2}{c}{$\mathbf{R}^{2}$} \\
\hline Swiss chard & $-422.973+76.199$ & $22.7520+2.4152$ & $8.3050+2.8130$ \\
Beetroot & $-193.518+22.244$ & $8.6327+1.3792$ & $14.0176+1.8187$ & 0.92 \\
Sweet-potato & $136.8524+5.2847$ & $2.6800+0.6159$ & $2.5640+0.6874$ & 0.93 \\
Potato & $13.9633+1.561$ & $1.662+0.7165$ & $5.2688+0.8986$ & 0.966 \\
\hline
\end{tabular}

LA: leaf area, L: leaf length, W: leaf width, SE: Standard Error. $* * * \mathrm{R}^{2}$ and all $\mathrm{SE}$ values are significant at $\mathrm{P}<0.001$

$$
\begin{gathered}
\text { AREA }\left(\mathrm{cm}^{2}\right)=-422.973+22.7520 \mathrm{~L}(\mathrm{~cm})+8.3050 \mathrm{~W}(\mathrm{~cm}) \\
\text { AREA }\left(\mathrm{cm}^{2}\right)=-193.518+8.6327 \mathrm{~L}(\mathrm{~cm})+14.0176 \mathrm{~W}(\mathrm{~cm}) \\
\text { AREA }\left(\mathrm{cm}^{2}\right)=136.8524+2.68 \mathrm{~L}(\mathrm{~cm})+2.564 \mathrm{~W}(\mathrm{~cm}) \\
\text { AREA }\left(\mathrm{cm}^{2}\right)=13.9633+1.662 \mathrm{~L}(\mathrm{~cm})+5.2688 \mathrm{~W}(\mathrm{~cm})
\end{gathered}
$$

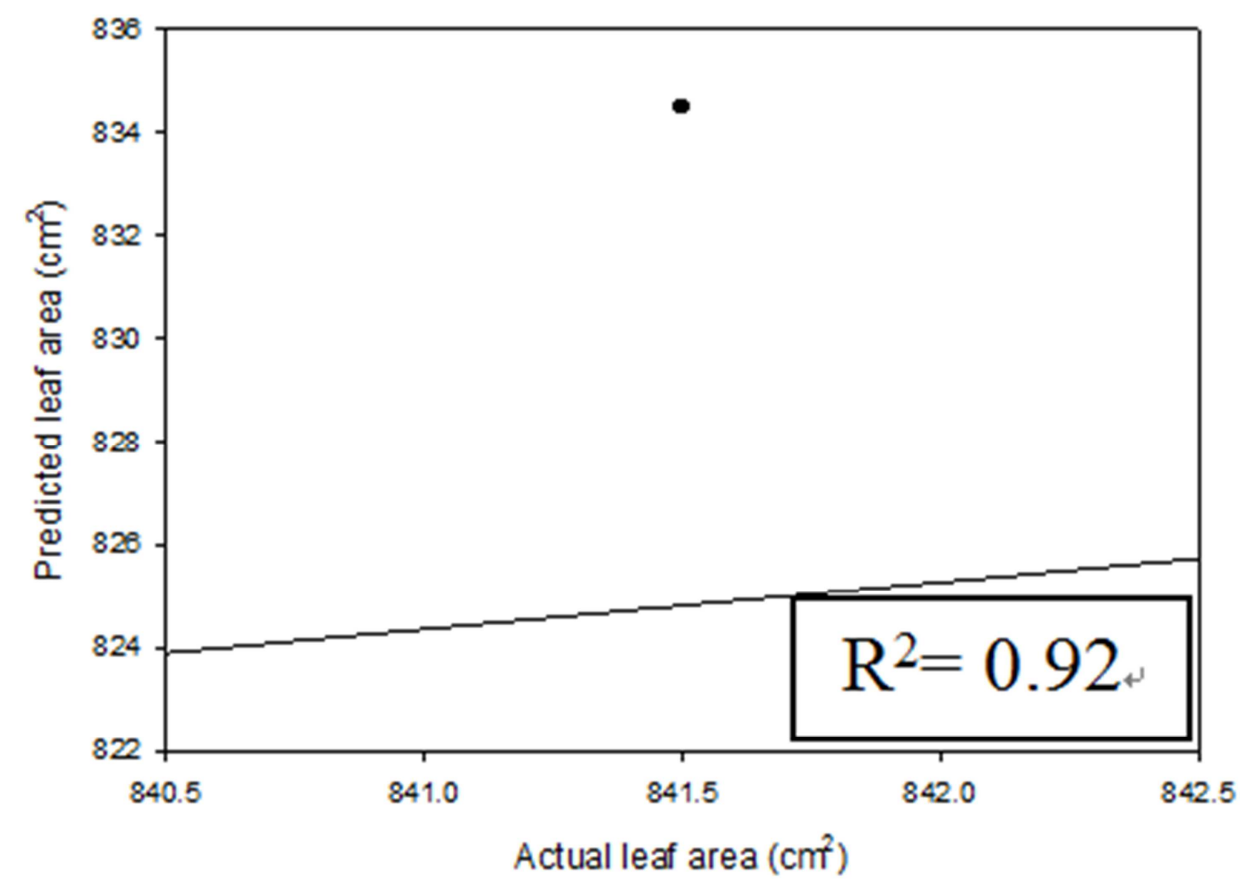

Figure 8. Relationship between actual (x axis) and predicted (y axis) leaf area in Swisschard. 

Area for Most Commonly Grown Vegetable Crops in Ethiopia

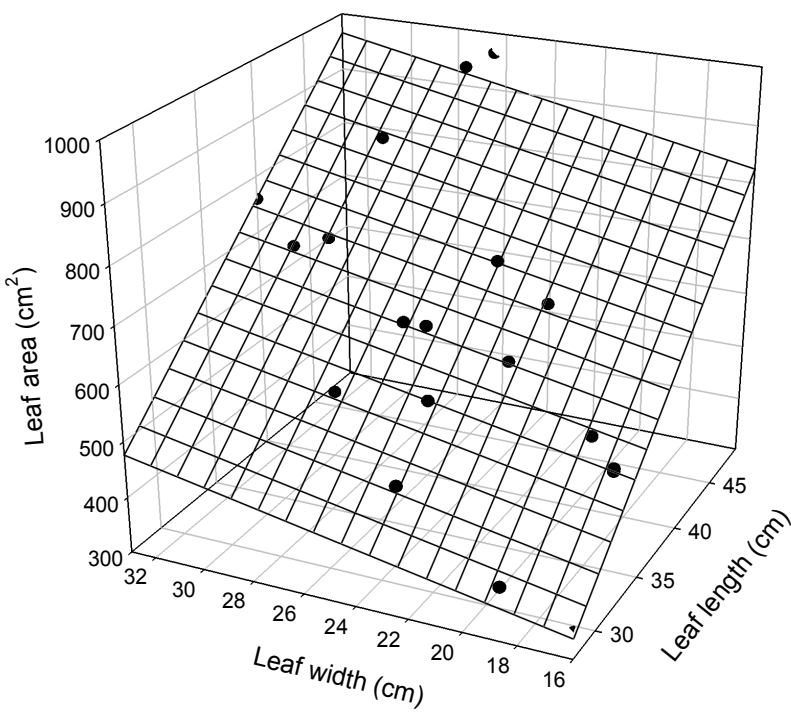

Figure 9. Model calibration for Swisschard.

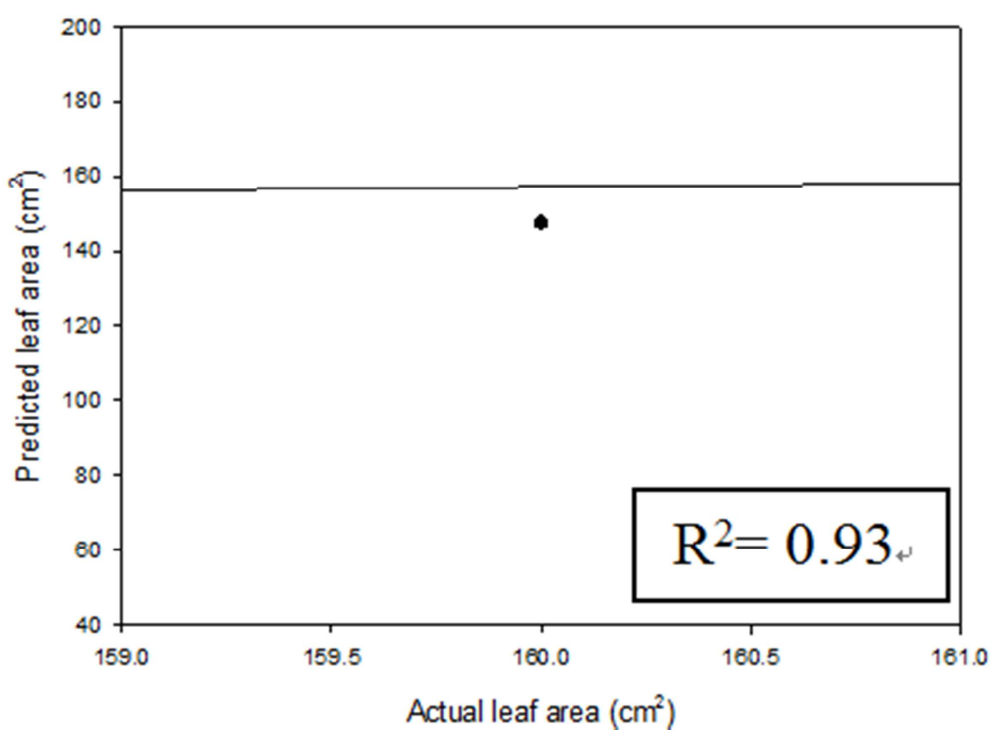

Figure 10. Relationship between actual (x axis) and predicted (y axis) leaf area in beet-root.

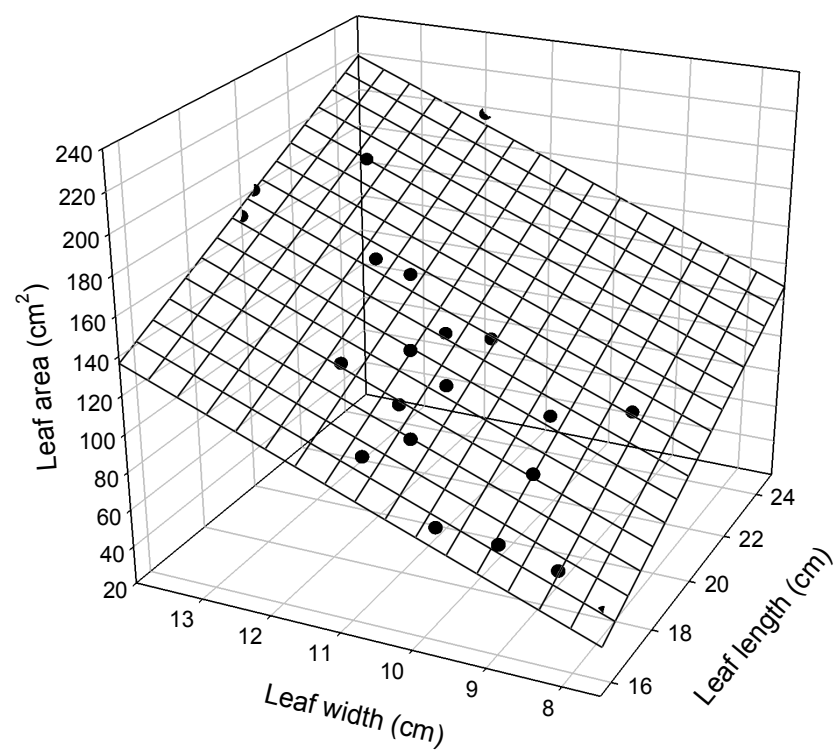

Figure 11. Model calibration for Beet root. 


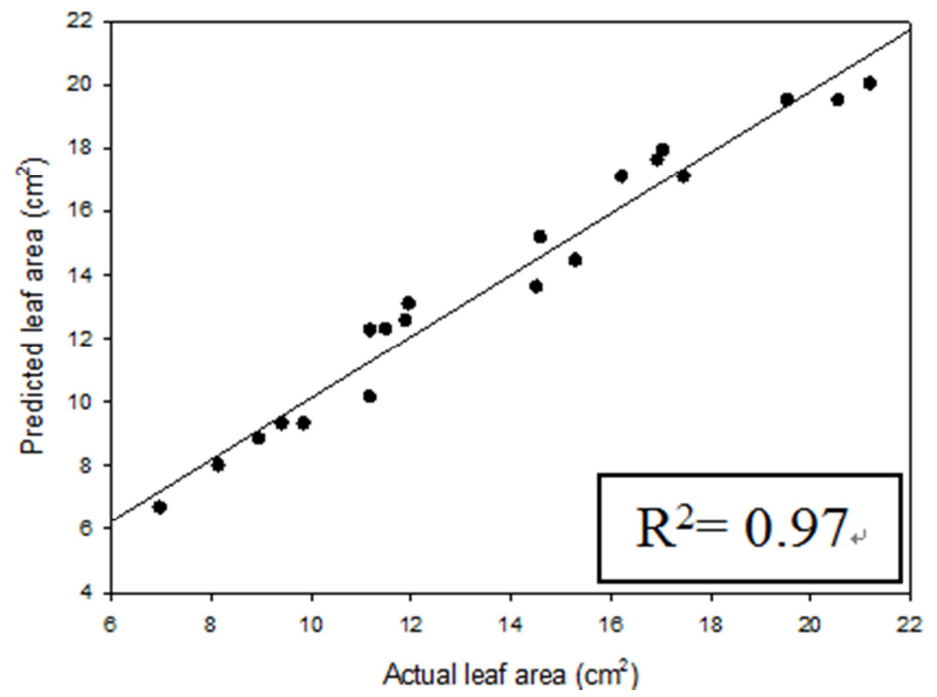

Figure 12. Relationship between actual (x axis) and predicted (y axis) leaf area in Potato.

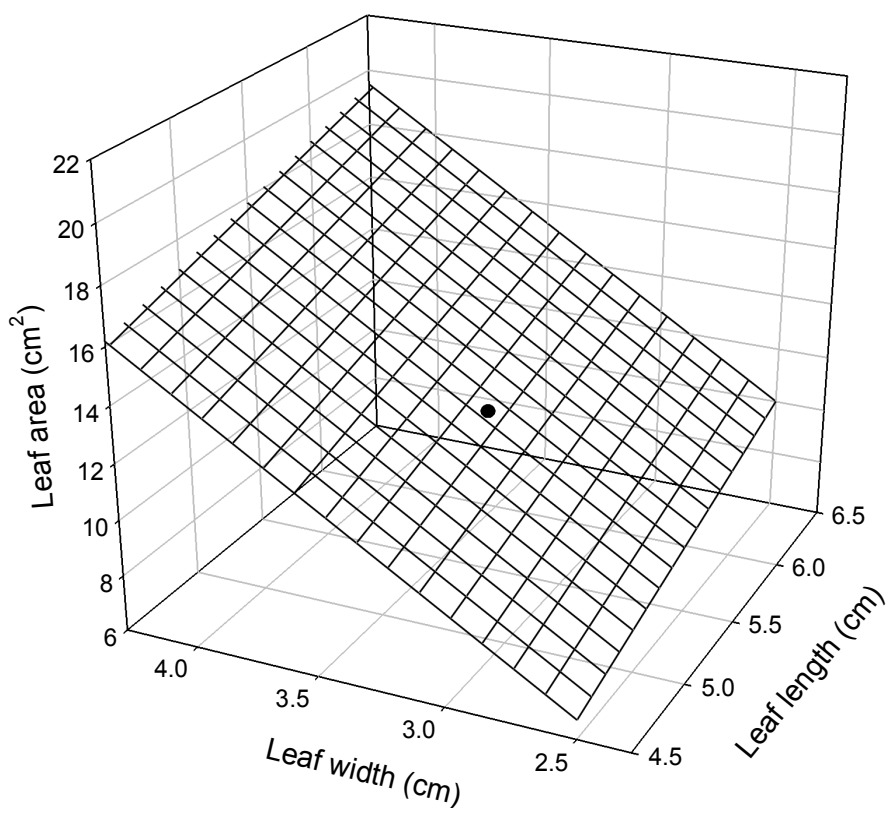

Figure 13. Model calibration for Potato.

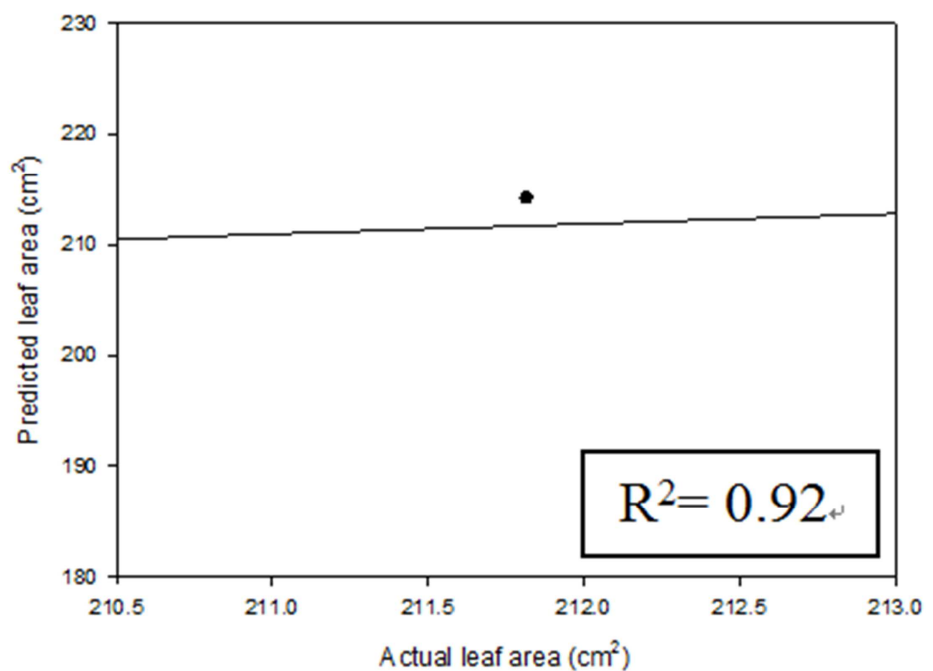

Figure 14. Relationship between actual (x axis) and predicted (y axis) leaf area in Sweet-potato. 


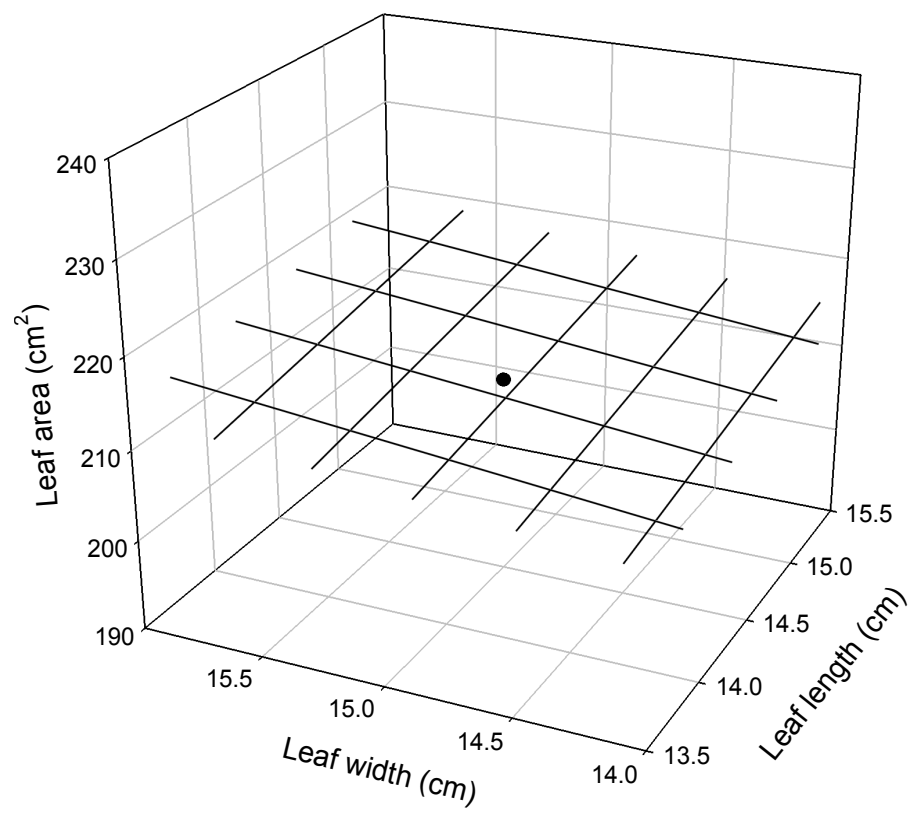

Figure 15. Model calibration for Sweet potato (Data transformed with log).

\subsection{Leaf Area Model for Onion}

For developing the best fit model for the case of onion leaf width and area were multiplied by two, assuming longitudinal dissecting and stretching the $3 \mathrm{D}$ lanceolate cylindrical structure of onion leaves to $2 \mathrm{D}$ plate.

The best fitting model for both of the two species was obtained with PLANE multiple regression equation $\left(\mathrm{R}^{2}=\right.$
0.924; $\mathrm{MSE}=25.04 ; P<0.001$. A very close relationship between actual and predicted leaf area for onion was found in this study (Figure 16 and 17). For the case of onion it was also found that most of the variations in leaf area values were explained by the selected parameters which are leaf length and leaf width (Table 4).

Table 4. The equation of leaf area $L A=y 0+(a \times L)+(b \times W)$ for Allium sp. Tested.

\begin{tabular}{lllll}
\hline Genotypes & $\mathbf{y 0}+\mathbf{S E}$ & $\mathbf{a}+\mathbf{S E}$ & $\mathbf{b}+\mathbf{S E}$ & $\mathbf{R}^{2}$ \\
\hline Onion & $-23.1534+5.324$ & $1.1023+0.1899$ & $16.1561+2.3401$ & 0.924 \\
\hline
\end{tabular}

LA: leaf area, L: leaf length, W: leaf width, SE: Standard Error. $* * * \mathrm{R}^{2}$ and all SE values are significant at $\mathrm{P}<0.001$

$$
\operatorname{AREA}\left(\mathrm{cm}^{2}\right)=-23.1534+1.1023 \mathrm{~L}(\mathrm{~cm})+16.1561 \mathrm{~W}(\mathrm{~cm})
$$

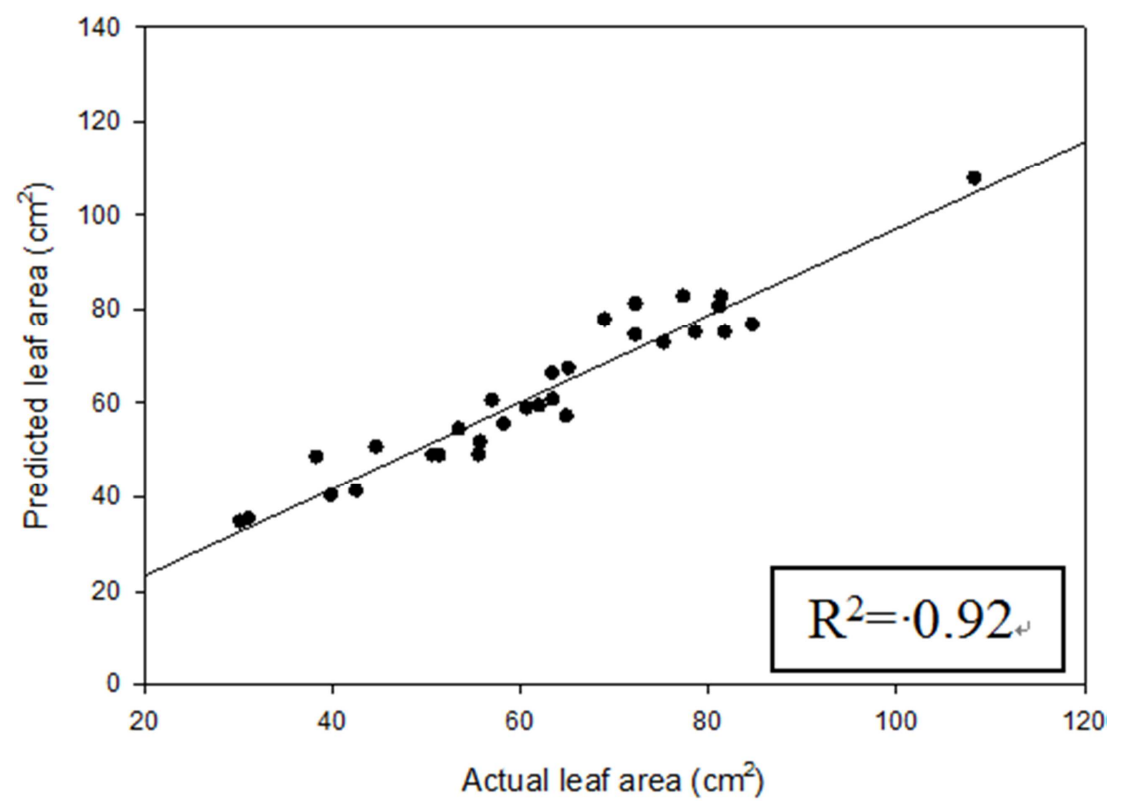

Figure 16. Onion Actual vs. predicted relationship. 


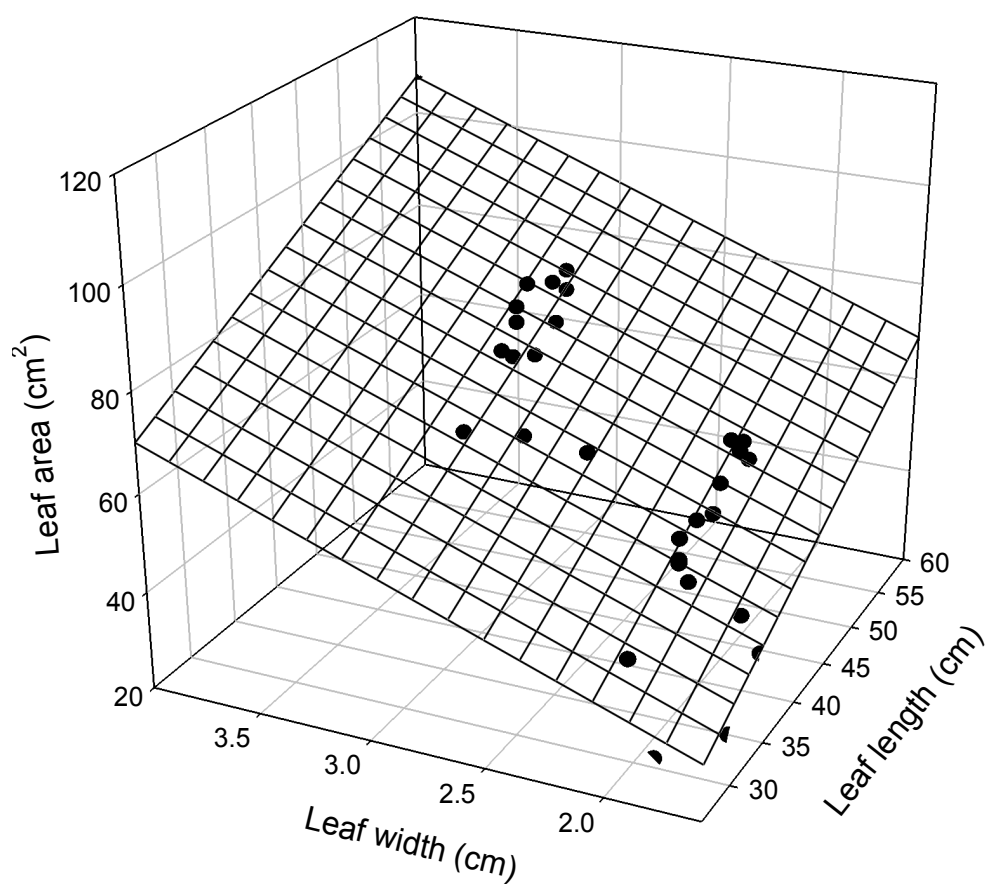

Figure 17. Model calibration for onion.

\subsection{Leaf Area Model for Cabbage}

Model calibration was also conducted for most commonly grown leafy vegetable of cabbage. Leaf $\mathrm{W}$, leaf $\mathrm{L}$ and functions of these dimensions were significantly $(\mathrm{P}<0.001)$ correlated with LA (Table 5). Since the leaf structure of cabbage is more or less a circular shape, model calibration was conducted by taking half the measurements of the length and width of the cabbage to derive the formula for a circle. Based on that Leaf $\mathrm{W}$, leaf $\mathrm{L}$ and functions of these dimensions were significantly $(\mathrm{P}<0.001)$ correlated with LA (Table 5).

Table 5. The equation of leaf area $L A=y 0+(a * x * y)$ for Cabbage.

\begin{tabular}{llll}
\hline Genotypes & $\mathbf{y 0}+\mathbf{S E}$ & $\mathbf{a}+\mathbf{S E}$ & $\mathbf{R}^{2}$ \\
\hline Cabbage & $-260.265+23.1937$ & $27.1145+1.1694$ & 0.97 \\
\hline
\end{tabular}

LA: leaf area, L: leaf length, W: leaf width, SE: Standard Error. $* * * \mathrm{R}^{2}$ and all SE values are significant at $\mathrm{P}<0.001$

$$
\operatorname{AREA}\left(\mathrm{cm}^{2}\right)=-260.265+27.1145 \mathrm{LW}\left(\mathrm{cm}^{2}\right)
$$

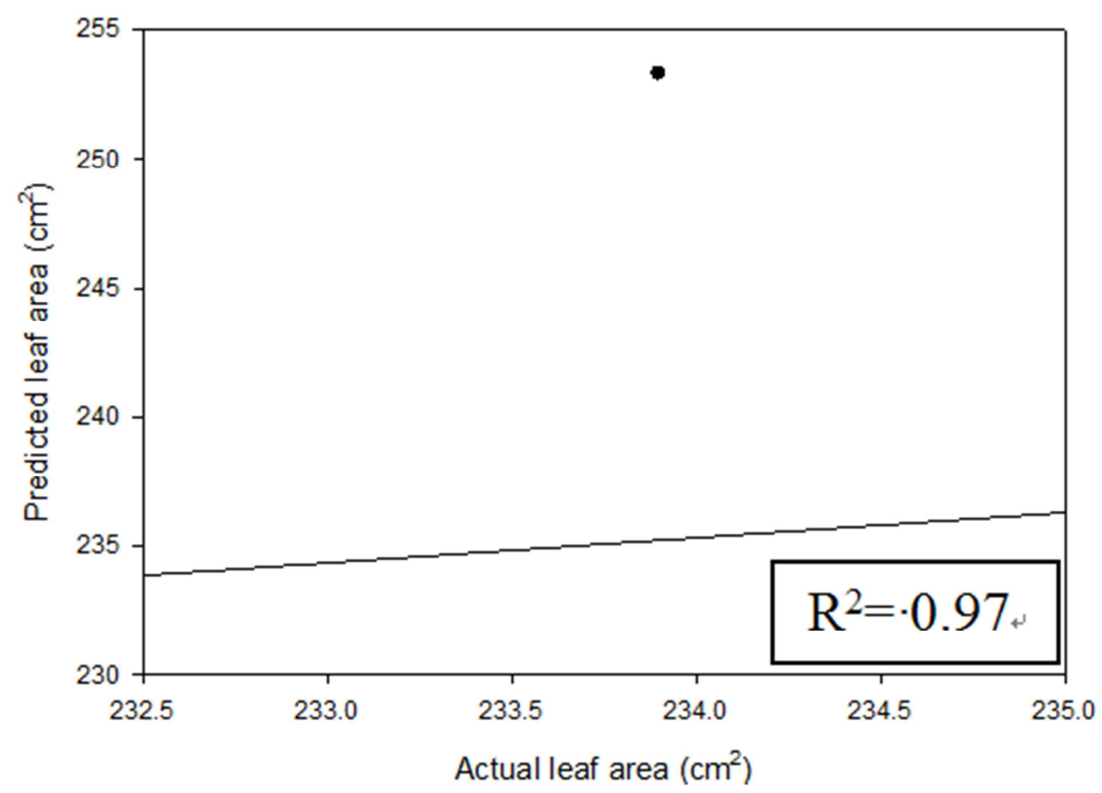

Figure 18. Cabbage actual vs. predicted relationship. 


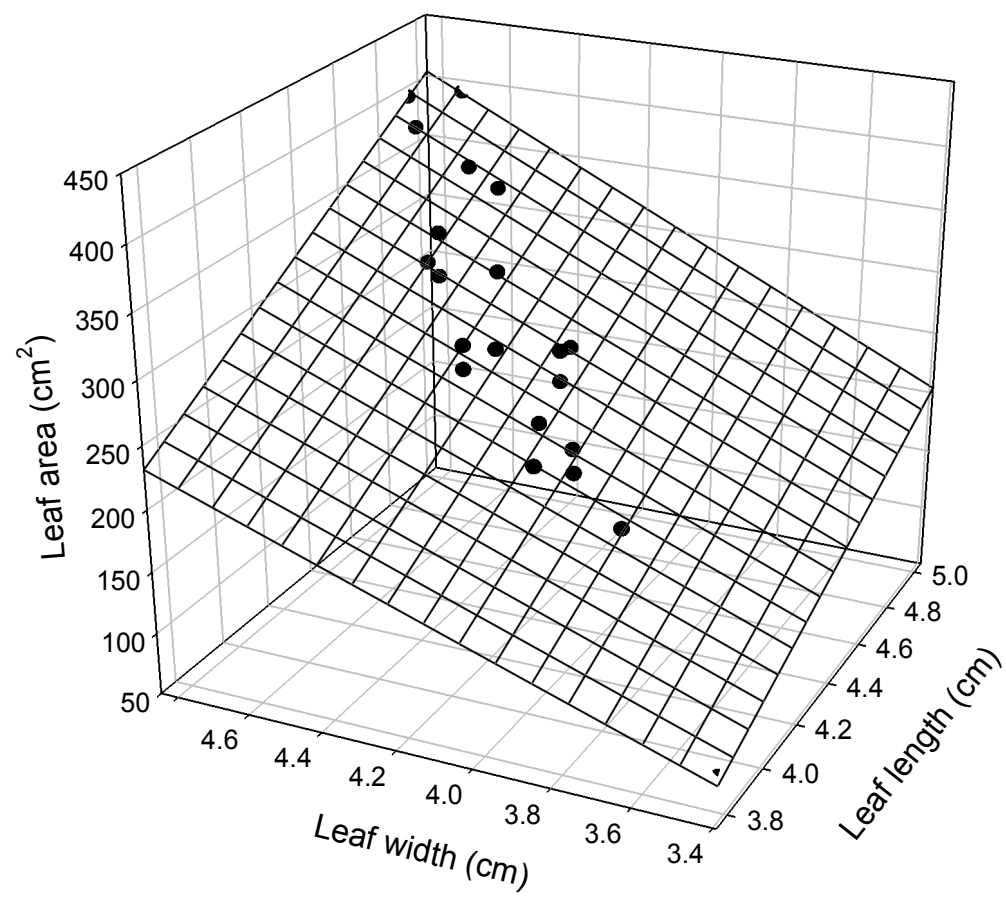

Figure 19. Model calibration for Cabbage.

\subsection{Leaf Area Model for Snapbean}

The best fitting model for both of the two species was obtained with PARABLOID multiple regression equation $\mathrm{R}^{2}$ $=0.966 ; \mathrm{MSE}=0.77 ; P<0.05$.

Table 6. The equation of leaf area $L A=y 0+(a \times L) *(b \times W)$ for F. vulgaris sp. Tested.

\begin{tabular}{lllllll}
\hline Genotypes & $\mathbf{y 0}+\mathbf{S E}$ & $\mathbf{a}+\mathbf{S E}$ & $\mathbf{b}+\mathbf{S E}$ & $\mathbf{c}+\mathbf{S E}$ & $\mathbf{d}+\mathbf{S E}$ & $\mathbf{R}^{\mathbf{2}}$ \\
\hline Snap-bean & $63.85+20.47$ & $-13.47+3.99$ & $7.34+2.41$ & $0.645+0.16$ & $-0.012+20.16$ & 0.996 \\
\hline
\end{tabular}

LA: leaf area, L: leaf length, W: leaf width, SE: Standard Error. ${ }^{* * *} \mathrm{R}^{2}$ and all $\mathrm{SE}$ values are significant at $\mathrm{P}<0.05$

$$
\operatorname{AREA}\left(\mathrm{cm}^{2}\right)=68.85-13.47 \mathrm{~L}(\mathrm{~cm})+7.34 \mathrm{~W}+0.645 \mathrm{~L}^{2}(\mathrm{~cm})-0.012 \mathrm{~W}^{2}(\mathrm{~cm})
$$

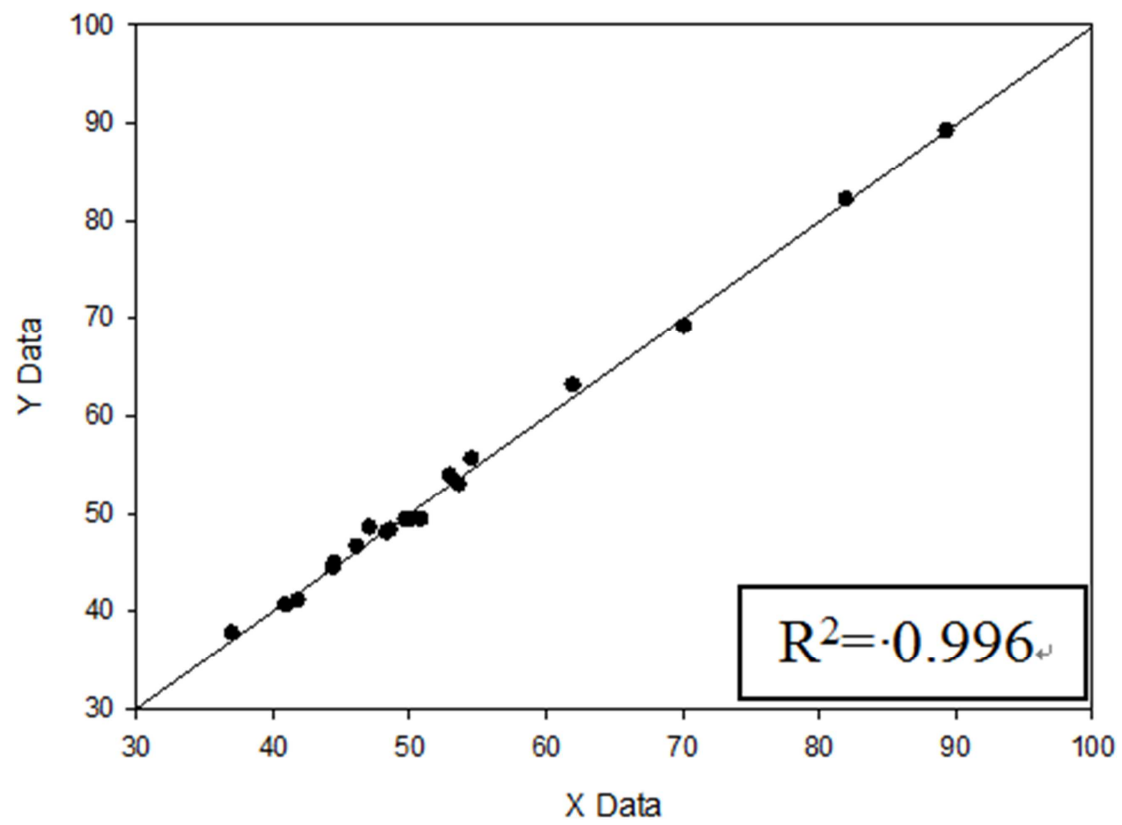

Figure 20. Snapbean actual vs. predicted relationship. 


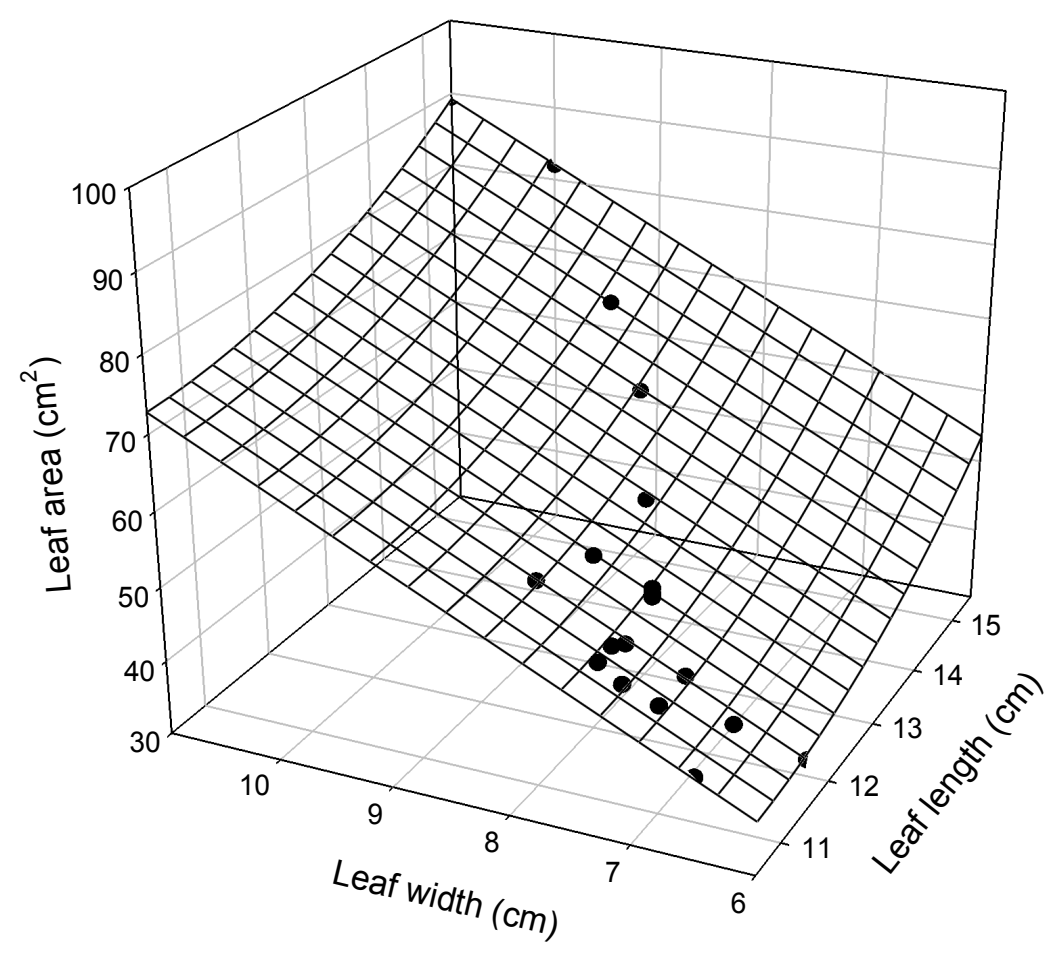

Figure 21. Model calibration for Snapbean.

\section{Conclusion}

Leaf area is an important variable for most physiological and agronomic studies involving plant growth, light interception, photosynthetic efficiency, evapotranspiration and response to fertilizers and irrigation. Plant yield and quality are affected by photosynthesis and transpiration rate, which are closely related to total leaf area.

The relationships were evaluated by fitting regression models with the multiple regression procedure of SIGMAPLOT 10 and in addition EXCEL and SPSS software were also used.

The internal validity of the models was tested by coefficient of determination $\left(\mathrm{R}^{2}\right)$, mean square error (MSE), the prediction sum of squares (PRESS), Durbin-Watson Statistic, Normality test, K-S Statistic, and Constant Variance Test. Residuals were analyzed to determine the presence of outliers and non-constant error variance.

A standard method (LICOR LI-3000C) was also used for measuring the actual areas of the leaves and predicted leaf area were derived as affected by leaf length and leaf width. The produced leaf area prediction models in the present study are:

AREA $\left(\mathrm{cm}^{2}\right)=-16.8821+2.5330 \mathrm{~L}(\mathrm{~cm})+4.5076 \mathrm{~W}(\mathrm{~cm})$ for Pepper Melka Awaze

AREA $\left(\mathrm{cm}^{2}\right)=-18.9428+2.2250 \mathrm{~L}(\mathrm{~cm})+5.7101 \mathrm{~W}(\mathrm{~cm})$ for Pepper Melka Zale

$\operatorname{AREA}\left(\mathrm{cm}^{2}\right)=136.8524+2.68 \mathrm{~L}(\mathrm{~cm})+2.564 \mathrm{~W}(\mathrm{~cm})$ for Sweet-potato

$\operatorname{AREA}\left(\mathrm{cm}^{2}\right)=-193.5176+8.6327 \mathrm{~L}(\mathrm{~cm})+14.0176 \mathrm{~W}(\mathrm{~cm})$ for Beetroot

$\operatorname{AREA}\left(\mathrm{cm}^{2}\right)=-23.1534+1.1023 \mathrm{~L}(\mathrm{~cm})+16.1561 \mathrm{~W}(\mathrm{~cm})$ for Onion

AREA $\left(\mathrm{cm}^{2}\right)=-260.265+27.115(\mathrm{~L}(\mathrm{~cm}) * \mathrm{~W}(\mathrm{~cm}))$ for Cabbage

$\operatorname{AREA}\left(\mathrm{cm}^{2}\right)=-422.973+22.752 \mathrm{~L}(\mathrm{~cm})+8.31 \mathrm{~W}(\mathrm{~cm})$ for Swisschard

$\operatorname{AREA}\left(\mathrm{cm}^{2}\right)=68.85-13.47 \mathrm{~L}(\mathrm{~cm})+7.34 \mathrm{~W}+0.645 \mathrm{~L}^{2}$ (cm) $-0.012 \mathrm{~W}^{2}(\mathrm{~cm})$ for Snapbean

$\mathrm{R}^{2}$ values $(0.989,0.976,0.917,0.926,0.924,0.966,0.917$, and 0.996 for the pepper Melka Awaze, Pepper Melka Zale, Sweetpotato, Beetroot, Onion, Cabbage, Swisschard and Snapbean respectively) and standard errors for all subsets of the independent variables were found to be significant at the $\mathrm{p}<0.001$ level.

As the understanding of plant growth and development has been increasing, such mathematical models will be very useful tools for the prediction of leaf area for many plants without the use of expensive devices. Thus, the models from the present study will enable researchers of plant growth modeling to predict leaf area non-destructively with the equations developed.

However, the equations produced should be validated with leaf samples taken from different environments and cultivars. The present models can be evaluated with leaf samples gathered from different growing periods and environments. In addition, care should be taken when using the produced models to predict the leaf areas of the plants in question to make certain that the leaf shapes are similar in form to those shown in Figure 2. 


\section{References}

[1] Gifford R. M., Thorne J. H., Witz W. D. and Giaquinta R. T. 1984. Crop productivity and photoassimilate partitioning. Science 225: 801-808.

[2] Pearce R. B., Brown R. H., and Blaser R. E. 1965. Relationships between leaf area index, light interception and net photosynthesis in orchardgrass. Crop Sci. 5: 553-556.

[3] Watson D. J. 1947. Comparative physiological studies on the growth of field crops: I. Variation in net assimilation rate and leaf area between species and varieties, and with and between years. Ann. Bot. (Lond.). 11: 41-76.

[4] Manivel L. and Weaver R. J. 1974. Biometric correlations between leaf area and length measurement of 'Grenache' grape leaves. Hort-Science 9: 27-28.

[5] De Swart E. A. M., Groenwold R., Kanne H. J., Stam P., Marcelis L. F. M. and Voorrips R. E. 2004. Non-destructive estimation of leaf area for different plant ages and accessions of Capsicum annuum L. Journal of Horticultural Science \& Biotechnology 79: 764-770.

[6] NeSmith D. S. 1991. Nondestructive leaf area estimation of rabbiteye blueberries. HortScience 26 (10): 1332.

[7] NeSmith D. S. 1992. Estimating summer squash leaf area nondestructively. HortScience 27 (1): 77.

[8] Gamiely S., Randle W. M., Mills H. A. and Smittle D. A. 1991. A Rapid and nondestructive method for estimating leaf area of onions. Hort Science, 26 (2): 206.

[9] Robbins N. S., Pharr D. M. 1987. Leaf area prediction models for cucumber from linear measurments. Hortscience, 22 (6): 1264-1266.

[10] Poethig, R. S. 1997. Leaf morphogenesis in flowering plants. The Plant Cell, 9, 1077-87.

[11] Antunes W. C., Pompelli M. F., Carretero D. M., and DaMatta F. M. 2008. Allometric models for non-destructive leaf area estimation in coffee (Coffea arabica and Coffea canephora). Annals of Applied Biology 153: 33-40.

[12] Kandiannan K., Parthasarathy U., Krishnamurthy K. S., Thankamani C. K. and Srinivasan V. 2009. Modelling individual leaf area of ginger (Zingiber officinale Roscoe) using leaf length and width. Scientia Horticulturae 120: 532-537.

[13] Spann T. M. and Heerema R. J. 2010. A simple method for nondestructive estimation of total shoot leaf area in tree fruit crops. Scientia Horticulturae. 125: 528-533.

[14] Rouphael Y., Mouneimne A. H., Rivera C. M., Cardarelli M., Marucci A. and Colla G. 2010. Allometric models for nondestructive leaf area estimation in grafted and un-grafted watermelon (Citrillus lanatus Thunb.) Journal of Food Agriculture and Environment. 8: 161-165.
[15] Schwarz D. and Kläring H. P. 2001. Allometry to estimate leaf area of tomato. Journal of Plant Nutrition. 24: 1291-1309.

[16] Verwijst T. and Wen D. Z. 1996. Leaf allometry of Salix viminalis during the first growing season. Tree Physiology, $16,655-60$.

[17] Demirsoy H., Demirsoy L., Uzun S. and Ersoy B. 2004. Nondestructive leaf area estimation in peach. European Journal of Horticultural Science 69: 144-146.

[18] Serdar U. and Demirsoy H. 2006. Non-destructive leaf area estimation in chestnut. Scientia Horticulturae. 108: 227-230.

[19] Cristofori V., Fallovo C., Mendoza-De Gyves E., Rivera C. M., Bignami C., and Rouphael Y. 2008. Non-destructive, analogue model for leaf area estimation in persimmon (Diospyros kaki L. f.) based on leaf length and width measurement. European Journal of Horticultural Science 73: 216-221.

[20] Mendoza-de Gyves E., Rouphael Y., Cristofori V. and Rosana Mira F. 2007. A non-destructive, simple and accurate model for estimating the individual leaf area of kiwi (Actinidia deliciosa). Fruits 62: 171-176.

[21] Fallovo C., Cristofori V., Mendoza-De Gyves E., Rivera C. M., Fanasca S. and Bignami C. 2008. Leaf area estimation model for small fruits from linear measurements. Hort Science 43: 2263-2267.

[22] Salerno A., Rivera C. M. Rouphael Y. Colla G. Cardarelli M. and Pierandrei F. 2005. Leaf area estimation of radish from linear measurements. Advances in Horticultural Science. 19: 213-215.

[23] Rivera C. M., Rouphael Y., Cardarelli M. and Colla G. 2007. A simple and accurate equation for estimating individual leaf area of eggplant from linear measurements. European Journal of Horticultural Science 70: 228-230.

[24] Wikipidia, 2013. Hawassa agro-ecology. (http://www.fao.or /GIE WS). (Accessed on 21 July 2000)

[25] Sokal R R \& Rohif F I. 1981. Biometry: the principles and practice of statistics in biological research. San Francisco: W. H. Freeman, 1969. 776 p. [Department of Ecology and Evolution, State University of New York, Stony Brook, NYJ.

[26] Sezgin U. and Hüseyin Ç. 1999. Leaf Area Prediction Models (Uzçelik-I) For Different Horticultural Plants. Tr. J. of Agriculture and Forestry. 23: 645-650.

[27] Sadik S. K., AL-Taweel A. A, and Dhyeab N. S. 2011. New Computer Program for Estimating Leaf Area of Several Vegetable Crops. American-Eurasian Journal of Sustainable Agriculture, 5 (2): 304-309.

[28] Erkut P. 2007. Non-destructive leaf area estimation model for Snap bean (Vicia Snap L.). Scientia Horticulturae. 113: 322328. 